\title{
Satellite Lesion
}

National Cancer Institute

\section{Source}

National Cancer Institute. Satellite Lesion. NCI Thesaurus. Code C159276.

Nodules of melanoma located more than $0.05 \mathrm{~mm}$ from the primary lesion. 